\title{
CORRECTIVE CONTRAST IN RUSSIAN, IN CONTRAST
}

\author{
KATJA JASINSKAJA \\ University of Heidelberg
}

\section{A B S T R ACT}

In many languages, correction (e.g. John didn't go to Paris, but to Berlin) and various kinds of contrastive relations are often expressed by the same marker (e.g. but in English). In Russian, correction is marked by the conjunction $a$ as part of what is often believed to be a fixed collocation ne ..., a ... 'not ..., but...', but conjunction a can also be used to encode, for instance, contrastive comparison Oleg ljubit futbol, a Roma basketbol 'Oleg likes football, and Roma likes basketball'. This paper addresses two issues. First, it tries to define a single 'meaning' of $a$ that covers both its contrastive and corrective uses. Second, concentrating on the differences between Russian and English, it investigates the structure of the contrast-correction semantic space to predict which of a range of contrast markers of a given language are more likely to be used in the correction function than the others.

\section{[1] INTRODUCTION}

This paper is concerned with corrective uses of contrastive markers, such as the Russian conjunction $a$ and the English conjunction but, illustrated in (1) and (2), respectively. It is characteristic for these uses that some contextually salient proposition is explicitly negated in one conjunct (John didn't go to Paris), while the other conjunct (to Berlin) presents an element that should "replace" the wrong part of the negated proposition (to Paris). ${ }^{1}$

(1) a. Oleg ezdil ne v Pariž, a v Berlin Oleg went not to Paris but to Berlin

b. Oleg ezdil v Berlin, a ne v Pariž

Oleg went to Berlin but not to Paris

(2) John didn't go to Paris, but to Berlin.

[1] In German this function is unambiguously expressed by the conjunction sondern, (i). This can be used as a heuristic if it helps to understand our terminology: correction is roughly the function that is expressed by sondern in German.

(i) Hans ist nicht nach Paris sondern nach Berlin gefahren

Hans is not to Paris but to Berlin gone 
This understanding of the term correction is common in descriptive and typological literature (e.g. Malchukov 2004; Mauri 2008), where it figures next to the additive and the adversative type in various functional classifications of coordinative constructions. To prevent terminological confusion, this notion should be distinguished from the speech act of correction in e.g. Asher and Lascarides (2003, pp. 345-350), such as the utterance (a) of speaker B in (3).

(3) A: They gave Peter the new computer.

B: a. No, they gave JoHn the new computer.

b. No, they didn't give it to PETER, but to JOHN.

of course, correction as a type of coordinative construction in (1)-(2) can be used to perform correction as a speech act, cf. (b) by speaker B in (3). One might even argue that from an evolutionary point of view this is the primary use of corrective coordination. However, both corrective coordination has other uses, and the correcting speech act can be done by other means. ${ }^{2}$ The focus of this paper is on corrective coordination.

Apart from correction, the Russian conjunction $a$ has other functions which all lie in the domain of contrast taken broadly. Work on $a$ in Russian linguistics has mainly concentrated on these other functions of $a$ (Kreidlin and Paducheva 1974a,b; Sannikov 1989; Fougeron 1990; Uryson 2002, among others), while the corrective function has usually been attributed to a fixed collocation $n e . . . a / a$ $n e$ consisting of $a$ and the negative particle $n e$, and was excluded from the general analyses of $a$. However, it is a common pattern across languages that the same marker is used for correction and for (one or other type of) contrast-the English but is another famous case-so a reduction of correction to a special case of contrast is an obvious thing to try. This is the goal of the present paper. We present an attempt to derive the properties of the corrective uses of $a$ from the general characteristics of $a$ as a contrastive marker, the semantics and pragmatics of negation, and the properties of the context of use. In doing so we will always keep an eye on the English but as another marker that combines corrective and contrastive uses. Although not all of the findings about Russian corrections can be generalised to the English case, many nevertheless can.

This paper is structured as follows. Section [2] takes a closer look at the crosslinguistic regularities in correction marking, particularly at the question which other functions from the contrast semantic space correction markers tend to have. Section [3] briefly recapitulates the theory of contrast from Jasinskaja and Zeevat $(2008,2009)$, while in section [4] that theory is applied to correction. Finally, section [5] presents the conclusions and discusses further questions raised by this study.

[2] See Kasimir (2006) for detailed discussion of the terminological issue. 


\section{[2] CORRECTION MARKING ACROSS LANGUAGES}

Some languages do not mark correction at all, i.e. correction is expressed by simple juxtaposition of a negative and a positive sentence, which is also possible in English: John didn't go to Paris. He went to Berlin. Other languages have dedicated markers of correction, i.e. markers that unambiguously express correction and nothing else, such as the German sondern, the Spanish sino, etc. Yet other languages use the same marker for correction and some other functions. Among those languages, correction is frequently coupled with functions that can be characterised as contrastive in one or another sense. Russian and English clearly belong to this group. This section will first present the most important distinctions between various kinds of contrast. This will make it possible to adequately describe the similarities and differences between (the non-corrective uses of) the Russian $a$ and the English but. Then the most relevant theoretical perspectives upon the emerging picture will be presented.

\section{[2.1] Non-corrective uses of correction markers}

ADVERSATIVE: The first group of uses includes at least two relevant subgroups. The first one covers the 'prototypical' instances of Lakoff's (1971) denial of expectation, i.e. cases where the second conjunct denies some normal consequence of the situation presented in the first conjunct, as in (4), where being short usually implies bad performance in basketball, but this expectation is denied. In English, this function is expressed by but, the same marker that is used for correction, while the Russian adversative marker is no, a different one from the correction marker $a$.

(4) John is short, but he is good at basketball.

The second subgroup includes the so-called argumentative uses of but and the Russian no (Anscombre and Ducrot 1977). The argumentative function is fulfilled where the conjuncts $A$ and $B$ present an argument and a counterargument for a claim $C$. E.g. in (5), the fact that the ring is beautiful normally implies that we should buy it, but the fact that it is expensive implies that we shouldn't.

(5) This ring is beautiful, but expensive.

There has been a lot of effort to reduce both types of use either to denial of expectation or to the argumentative function. The theory summarised in section [3] presupposes a reduction of the latter kind. In any case, the distinction is irrelevant for our present purposes, both subgroups together constitute one class of non-corrective uses that we will refer to as adversative.

CONTRASTIVE COMPARISON: This term taken from Blakemore (1987) will be used to describe the second group of cases, where the conjoined clauses are presented 
in a parallel fashion, so as to highlight the similarities and differences between them. There is no restriction to two conjuncts here, there can be three and more, as in (6). Crucially, the conjuncts must differ in two (or more) constituents, e.g. the subject and the object of liking in (6), leading to a contrastive topic-focus structure: Oleg, Roma and Vera are the contrastive topics, football, basketball and tennis are the contrastive foci. Contrastive comparison in the present sense corresponds closely to what is known in Russian linguistics as the sopostavitel'noe značenie ('comparative meaning') of the conjunction a (Kreidlin and Paducheva 1974b). Thus this function is conveyed in Russian by the same marker as is used for correction, while English uses a simple additive marker and.

(6) Oleg ljubit futbol, Roma basketbol, a Vera tennis Oleg likes football Roma basketball and Vera tennis Oleg likes football, Roma likes basketball, and Vera likes tennis.

Examples very similar to (6) with but instead of and, e.g. John is tall, but Bill is small, also appear in the literature under labels such as semantic opposition (Lakoff 1971), or formal contrast (Asher and Lascarides 2003). These labels, as well as Blakemore's contrastive comparison were introduced originally to distinguish such uses of but, which are also characterised primarily by parallel presentation and contrasting of the conjuncts from the proper adversative uses illustrated above. Indeed it seems possible to use but in the function we have just defined when the number of conjoined clauses is exactly two (Foolen 1991). However, as will become clear presently, there is a subtle difference between those uses of but and contrastive comparison in our definition.

As a final terminological remark, it is not clear that the requirement of at least two points of difference between the conjuncts and the contrastive topic-focus structure plays any important role in the original definitions of contrastive comparison or semantic opposition. It does, however, in our definition, because this is the feature that licenses the use of $a$ in Russian. If the conjuncts only differ along one dimension, as in John did the dishes and went shopping, where did the dishes and went shopping present distinct actions, but the actor is the same, a different conjunction is used in Russian-a simple additive marker $i$ (see Jasinskaja and Zeevat 2008, for detailed illustration).

FOOLEN'S TESTS: The third relevant type of contrast, typically expressed by but in English, does not have any widely accepted label of its own and has rarely been distinguished as a special function, or use, or meaning of contrastive conjunctions. It is very similar to contrastive comparison in that the conjoined propositions also have to differ along two dimensions. However, along one of those dimensions the values should not just be different, but in some sense opposite, e.g. the antonyms in (7), the positive vs. negative polarity in (8). 
(7) John is tall, but Bill is small.

(8) John likes football, but Bill doesn't.

The opposition can also be pragmatic in nature, as in (9) where one conjunct confirms and the other denies a contextually salient proposition: John lives in Amsterdam confirms Speaker A's expectation that John lives in Amsterdam, while Peter lives in Rotterdam denies the expectation that Peter lives in Amsterdam, too, so in this case it is a way of saying that Peter does not live in Amsterdam (opposite polarity). Note that in (10) no assumptions of Speaker A are denied, i.e. there is no motivation for polar interpretation of the conjuncts, therefore and is the preferred conjunction. The contextual tests in (9) and (10) were introduced by Foolen (1991) to argue that but in all its uses involves a denial of expectation, as in (9). Whether or not we want to subscribe to Foolen's reduction of but to denial of expectation, his tests do draw the crucial distinction between contrastive comparison (10) and the type of contrast in question (9), for which we will reserve the term opposition. In both cases the conjoined propositions differ along two dimensions at least. However, in oppositions the values along one of those dimensions have to be polar.

(9) A: John and Peter both live in Amsterdam, don't they?

B: No. John lives in Amsterdam, but (?? and) Peter lives in Rotterdam.

A: John and Peter don't live in the same place, do they?

B: No. John lives in Amsterdam, and (?? but) Peter lives in Rotterdam.

Thus opposition in the present sense is expressed by but in English. It should be obvious that the "oppositeness" of the conjuncts implies that there can be only two, which is in accordance with but's restriction to two conjuncts.

In contrast, Russian uses $a$ in this function, the same marker as for contrastive comparison, and not the same as for denial of expectation. Apparently, the parallel presentation and the contrastive topic-focus structure turns out to be decisive for the choice of conjunction.

Finally, this section can be summarised as shown in Table 1 on the following page. Apart from correction, the Russian conjunction a marks contrastive comparison and opposition, while the English but marks opposition and adversative contrast. Thus both the Russian $a$ and the English but are markers of contrast, but they mark different types of contrast.

\section{[2.2] Typological theories of correction}

Why is correction often marked in the same way as contrast? And why does Russian use a contrastive comparison marker for correction, while English uses an 


\begin{tabular}{|l|c|c|c|}
\hline & CONTR. COMPARISON & OPPOSITION & ADVERSATIVE \\
\hline Russian & \multicolumn{2}{|c|}{$a$} & no \\
\hline English & and & \multicolumn{2}{c|}{ but } \\
\hline
\end{tabular}

TABLE 1: Russian and English contrast markers

adversative? In this section we take a brief look at typological theories that bear on these questions.

A well-established approach to describing multifunctionality patterns of grammatical markers across languages is based on conceptual, or semantic maps. This approach has also been applied to correction and contrast marking; we will review two recent proposals in this framework: Malchukov (2004) and Mauri (2008). The notion of semantic map assumed in those studies is most closely related to Haspelmath's (2003) proposal. The approach is summarised below in a rather simplified form which might not reflect amply its philosophical motivation, but is consistent with the way it is applied by Malchukov (2004) and Mauri (2008).

A semantic map is a contiguous graph, whose nodes represent the possible functions of grammatical markers (such as CONTRASTIVE COMPARISON, OPPOSITION, ADVERSATIVE from the previous section), and whose arcs connect "most closely related" or "most similar" functions. The standard assumption is that both the set of possible functions and this "closeness" or "similarity" relation are universal. The relation is the basis for predictions concerning which marker-function mappings are possible in natural languages. In its strong form, the claim is that the set of functions expressed by the same marker must be a contiguous subgraph of the semantic map. The arcs also have a diachronic interpretation: a marker can only acquire a new function that is immediately connected to one it already has, and cannot "jump" over functions in between. This development can occasionally create exceptions to the contiguity claim in its strong form: if marker $A$ acquires a new function formerly covered by marker $B$, it can split $B$ 's subgraph into two unconnected parts. ${ }^{3}$

The set of functions of a semantic map should be fine-grained enough to represent relevant differences in the usage of markers within a single language and across languages. If the meanings of two markers (in two languages) are equivalent, they are mapped to the same set of nodes; if the meanings are different, the sets of nodes must be different, too. Thinking of CONTRASTIVE COMPARISON, OPPOSITION and ADVERSATIVE as nodes of a semantic map, it becomes clear that having opposition separate from both other nodes is important to express the difference between the Russian and English contrastive conjunction systems, cf. Table 1 . In cases where more than one function is expressed by the same marker,

[3] The theoretical status of such exceptions is, however, a matter of debate. 
the approach is neutral with respect to the question whether those functions constitute different senses of that marker (a polysemous, or homonymous marker), or whether those functions are just different uses of a marker with a single abstract meaning.

The claim that there is a universal semantic map goes hand in hand with the assumption that the set of functions and the connections between them are somehow cognitively motivated, i.e. there are some fundamental characteristics of human thinking, or language processing, or communication, that determine which functions are likely to be expressed in natural languages and which of them are more likely to be expressed in the same way. However, semantic maps as such only represent claims about the existence of functions and relationships between them, but not about their nature. In some cases the nature of the relationship is well understood. In other cases it is less clear, so the semantic map is just the result of induction from polysemy patterns of markers from a representative sample of languages. ${ }^{4}$

Let's now consider the place of correction in relation to contrast in the semantic maps proposed by Malchukov (2004) and Mauri (2008), shown in figures 1 and 2 on the next page. Malchukov's function ADVERSATIVE is the same in all relevant respects as our notion of the adversative function. The function CONTRASTIVE, however, corresponds roughly to Lakoff's (1971) semantic opposition, and thus conflates our present notions of contrastive comparison and opposition. Mauri's opposition, in turn, corresponds closely to our contrastive comparison (not to our opposition!), while opposition in our sense and the adversative function are conflated under the label countereXPECTATIVE. ${ }^{5}$ Thus, Malchukov's claim is that whenever a contrast marker is used for correction it should be the same marker as is used to connect sentences with contrastive topic-focus structure, no matter whether the conjuncts are 'opposite' or just distinct along two dimensions (both being part of the CONTRASTIVE function). Mauri's map amounts to (almost) the same claim. Although contrastive comparison is separated from opposition in our sense (the latter being part of COUNTEREXPECTATIVE), CORRECTION is placed between them, and thus can share markers with either of them.

Although both maps are consistent with the Russian and English correction marking patterns, i.e. they do not create non-contiguous marking regions, cf. tables 2 and 3 on the following page, they leave space for improvement and some open questions. First, both maps do not cleanly delineate the functions of different contrast markers within Russian and English systems. Since Malchukov lumps together contrastive comparison and opposition, the subtle difference in the us-

[4] See Janda (2009) for critical discussion of the universality claims of the semantic maps approach.

[5] The '...' node in both figures stands for a set of functions including plain additive and temporal conjunction, i.e. functions covered by the non-contrastive uses of and in English and the conjunction $i$ in Russian. 


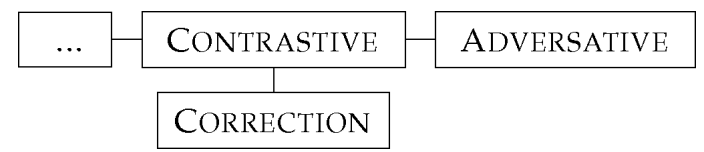

FIGURE 1: Correction in Malchukov's (2004) semantic map

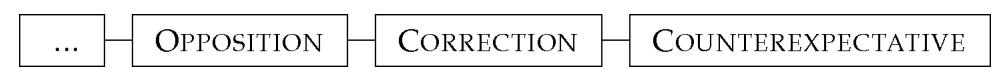

FIGURE 2: Correction in Mauri's (2008) semantic map

\begin{tabular}{|l|c|c|c|}
\hline & CORRECTION & CONTRASTIVE & ADVERSATIVE \\
\hline Russian & \multicolumn{3}{|c|}{$a$} \\
\hline \multirow{2}{*}{ English } & \multicolumn{3}{|c|}{ but } \\
\cline { 2 - 4 } & \multicolumn{3}{|c|}{ and } \\
\hline
\end{tabular}

TABLE 2: Russian and English marking patterns in Malchukov's map

\begin{tabular}{|l|c|c|c|}
\hline & OPPOSITION & CORRECTION & COUNTEREXPECTATIVE \\
\hline Russian & \multicolumn{2}{|c|}{$a$} & no \\
\hline English & and & & but \\
\hline
\end{tabular}

TABLE 3: Russian and English marking patterns in Mauri's map 


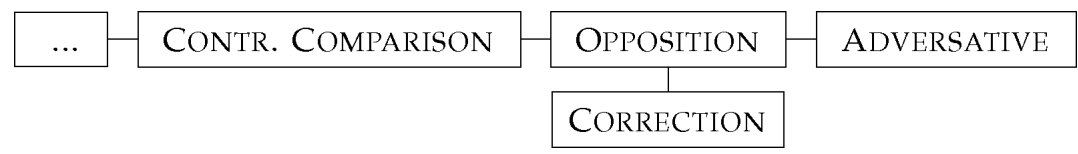

FIGURE 3: Correction and opposition in a semantic map

age of the English and and but observed by Foolen (1991) is not reflected by the map. Mauri's map, in turn, creates the wrong impression that the only difference between the Russian and the English systems is "on whose side" CORRECTION is. This is because Mauri follows Foolen in regarding opposition as a special case of denial of expectation and does not separate it from her COUNTEREXPECTATIVE function. However, Foolen's reductionist approach, which might be useful in finding a single abstract meaning for the English but, is not very helpful in constructing a semantic map. The distinctions that it blurs might be indeed spurious in English, but they are real in other languages, e.g. in Russian. As was pointed out above, another difference between the English and the Russian systems is in marking opposition, cf. table 1: in Russian both correction and opposition are coupled with contrastive comparison in $a$, whereas in English they are both coupled with the adversative in but. One might formulate a stronger hypothesis based on these observations, namely that CORRECTION is only related to OPPOSITION in our sense. A semantic map that suggests itself is shown in figure $3 .^{6}$ This map represents our (preliminary) answer to the question why Russian uses a contrastive comparison marker for correction, while English uses an adversative. Whenever a contrast marker is recruited for correction, it should be an opposition marker. Since in Russian OPPOSITION is coupled with CONTRASTIVE COMPARISON in $a$, the same marker is used for CORRECTION. Since in English OPPOSITION is coupled with the ADVERSATIVE function in but, CORRECTION is also expressed by but.

The second problem is not with the semantic maps as such, but with their motivation. What is the nature of the relationship between different contrast types? What makes CORRECTION and contrast, especially the OPPOSITION type of contrast so closely related? This is the central question to be addressed in this paper. To make this relationship explicit we will make use of the analytic tools of formal semantics. Only if CORRECTION and OPPOSITION can be represented as special cases of a single non-trivial category, or 'meaning', and only if the realisation of one or the other function can be predicted from context, can we talk about corrective uses of a general contrastive $a$, rather than a special corrective 'meaning' of $a$. In

[6] As will be shown in section [5] this semantic map is falsified once we consider a broader selection of languages, but it is consistent with the Russian and English data, so we will stick to it for the time being. 
order to answer this question, the next section presents a theory of contrast from our previous work, and section [4] integrates correction into that theory.

\section{[3] A THEORY OF CONTRAST}

The central idea of Jasinskaja and Zeevat $(2008,2009)$ is that additive and contrastive markers like and and but convey information about the discourse topics addressed by the clauses they connect, where discourse topics are represented as questions under discussion (QUD) along the lines of e.g. Roberts (1996) and Büring (2003). Questions are represented as sets of Hamblin-style alternatives (Hamblin 1973), e.g. the question Who smokes? corresponds to the set of mutually compatible possible answers $\{$ John smokes, Mary smokes, Bill smokes, ... $\}$. Contrast markers can indicate the type of question that their conjuncts answer. The question types relevant for the description of the English and Russian conjunction systems differ according to two main parameters: the number and the type of question variables. In terms of the number of variables, the most important distinction is between single and multiple variable questions, which corresponds to the number of dimensions in which the question alternatives differ. The canonical cases are single (Who snores?) vs. multiple wh-questions, e.g. Who likes what?, Who gave what to whom?, etc., respectively. In the most general form, the $x$ notation is used to refer to a single variable, $\vec{x}$ for an unspecified number of variables (a tuple of one or more), and $\langle\vec{x}, y\rangle$ for multiple variables (a tuple of two or more). The most important variable types are, informally, wh for various types of entities that can answer questions like who, what, when, etc., and the $y / n$ type for negative vs. positive polarity instantiated by negation and an identity operator of the same logical type. This is the variable type of yes/no-questions like Does John like football? and corresponds to the word whether in embedded questions. Abstracting away from the meanings of specific markers, let's apply this idea to the definition of the different types of contrast-CONTRASTIVE COMPARISON, OPPOSITION and ADVERSATIVE-which make up the semantic map proposed in the previous section in figure 3 on the previous page.

CONTRASTIVE COMPARISON: Two or more clauses stand in a relation of CONTRASTIVE COMPARISON to one another if (a) they address a discourse topic that can be represented as a double or multiple wh-question, i.e. a $\left\langle\vec{x}_{w h}, y_{w h}\right\rangle$-question, and (b) they give distinct answers to such a question so that the instantiations of each variable in the question are distinct. For example, in (6) repeated below, the QUD can be assumed to be Who likes what kind of sports? with two variables who and what kind of sports. Oleg, Roma and Vera are mutually distinct instantiations of the who-variable, while football, basketball, and tennis instantiate the what kind of sportsvariable and are also mutually distinct: 


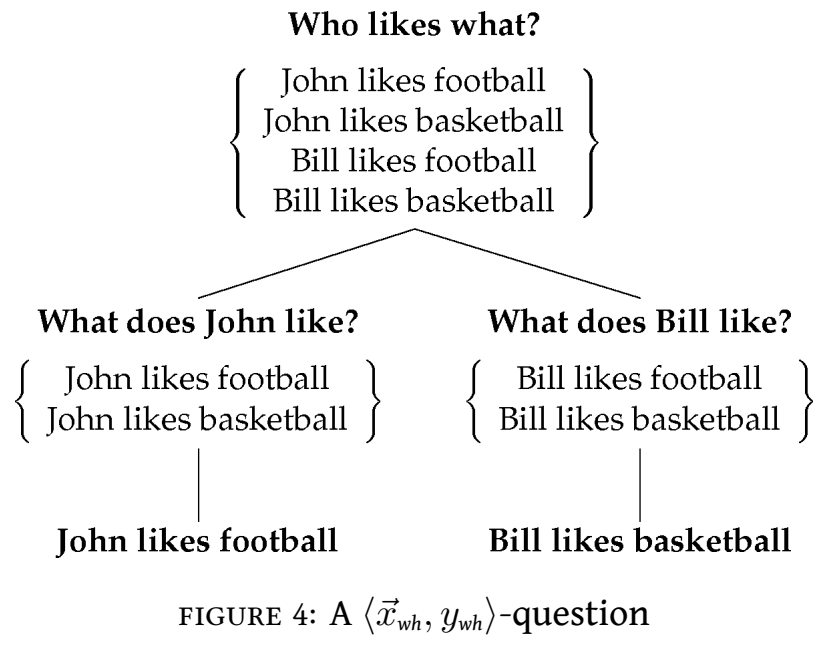

(11) Oleg ljubit futbol, Roma basketbol, a Vera tennis

Oleg likes football Roma basketball and Vera tennis

Oleg likes football, Roma likes basketball, and Vera likes tennis.

The alternative set of a similar double wh-question is shown in cf. figure 4. Notice that this set can be partitioned into subsets that correspond to single variable subquestions What does John like?, What does Bill like? This is what we will refer to as splitting up a question into subquestions, or a strategy in Roberts' (1996) and Büring's (2003) terminology.

OPPOSITION: The OPPOSITION relation also involves giving distinct answers to a double or multiple variable question, however one of those variables has to be of the yes/no type: $\left\langle\vec{x}_{w h}, y_{y / n}\right\rangle$. We will also refer to this type as wh-yes/no-questions. ${ }^{7}$ The alternative set of such a question is shown in figure 5 on the following page: the alternatives differ as to who likes or doesn't like football, and in the presence vs. absence of negation. Neither English, nor Russian (nor any other natural language we are aware of) can express this type of question by a simple interrogative sentence. A possible gloss one could give to the set of alternatives in figure 5 is Who "whether" likes football? In English, one can express this question either by conjoining a number of $y / n$-questions, as in figure 5 , or by conjoining two whquestions Who does and who doesn't like football? For the rest, the analogy between

[7] This is a necessary but not a sufficient condition for OPPOsition. As will be shown below, also ADVERSATIVES and CORRECTIONS address wh-yes/no-questions, but have to satisfy a number of additional conditions. To keep the functions in a semantic map mutually exclusive we will ultimately define opposition as a relation between answers to a wh-yes/no-question that is not adversative or corrective. 


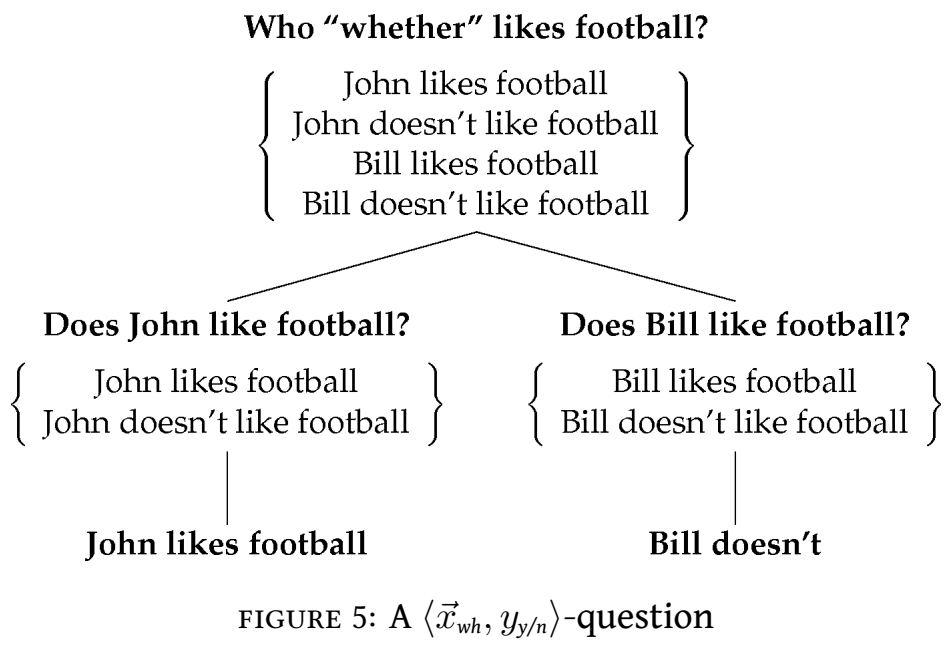

wh-yes/no-questions and standard multiple wh-questions is obvious, cf. figures 4 and $5 .^{8}$

The $y / n$ variable in the topic question is what accounts for the "oppositeness" of the clauses that stand in an opposition relation. It predicts that either one clause should be positive and the other negative as in (8) or in figure 5, or that one clause is used to deny an implicit supposition of the right form. E.g. in (9),

[8] Although the present representation of the discourse topic is inspired by Büring (2003), unlike Büring and more in line with Hamblin (1973) we assume that the alternative set of a yes/no-question contains both a positive and a negative alternative. Assuming that the alternative set of a question is partitioned by the alternative sets of its subquestions, this gives us that double wh-yes/no-questions also contain both positive and negative alternatives, cf. figure 5. If they only contained positive alternatives, then the wh-yes/no-question who "whether" likes football? would be indistinguishable from the single wh-question Who likes football? There are various semantic reasons for keeping yes/no-questions to just the positive alternative and one might even argue that double wh-whether interrogative sentences do not exist precisely because the alternative set containing both positive and negative alternatives is not a legitimate semantic object, while its positive subset is indistinguishable from the single wh-question. However, whyes/no-questions as pragmatic objects, i.e. as issues to be interested in, certainly do exist and are distinct from single wh-questions. In the first case, both the positive and the negative extension of the question predicate $P$ (for the question who "whether" $P$ ?, e.g. $\lambda x[x$ likes football $]$ in the present example) must be explicitly named. If some object is not named one may conclude that it is not relevant, but not that it is not $P$. In the second case, only the positive extension is asked for, while for the remaining relevant objects 'not $P$ ' is inferred by the process of exhaustive interpretation (e.g. Schulz and van Rooij 2006). Thus, including the negative alternatives gives us a representational handle on this pragmatic distinction (even if it does not per se explain it). 
repeated below, Peter lives in Rotterdam is a way of saying that Peter does not live in Amsterdam, and thus an answer to the question Does Peter live in Amsterdam? ${ }^{9}$

A: John and Peter both live in Amsterdam, don't they?

B: No. John lives in Amsterdam, but (?? and) Peter lives in Rotterdam.

Similarly, the $y / n$ variable is responsible for the restriction to exactly two clauses in an opposition relation, because there can only be two distinct answers to a yes/no-question-yes and no.

ADVERSATIVE: Finally, one of the necessary conditions for an ADVERSATIVE relation is that the clauses give distinct answers to a particular kind of $\left\langle x_{w h}, y_{y / n}\right\rangle$ question, which we called why-whether- or why-yes/no-questions in Jasinskaja and Zeevat $(2008,2009)$. For example, Why "whether" we should buy this ring? - [Why should we buy this ring?] It is beautiful, but [why shouldn't we buy this ring?] it is expensive. Further necessary conditions concern the kind of causal relation involved and the place of the wh and the $y / n$ variable in the structure of the alternatives. As is made explicit in (13), the alternatives all involve a causal relation between two statements expressed by a two-place operator BECAUSE, whose first argument is the cause, and whose second argument is the effect. In fact, this is not just a general BECAUSE, but its argumentative variety, i.e. an epistemic or a speech act BECAUSE in Sweetser's terminology (1990), so it would be more adequate to say that its second argument is a claim or suggestion, while its first argument gives support to that claim, i.e. the reason to think that it is true or the reason to accept the proposition.

$$
\left\{\begin{array}{l}
\text { BECAUSE (this ring is beautiful, we buy it) } \\
\text { BECAUSE(this ring is expensive, we buy it) } \\
\text { BECAUSE(this ring is beautiful, NEG(we buy it)) } \\
\text { BECAUSE(this ring is expensive, NEG(we buy it)) }
\end{array}\right\}
$$

The relevant question type must satisfy two more conditions. First, the wh variable of the question is the reason, i.e. first argument of BECAUSE. Second, the $y / n$

[9] For our purposes it does not matter that the question in (12)A is biased. After an unbiased question Does John live in Amsterdam, and does Peter live in Amsterdam, too? (cf. also (11) on p. 215 in Umbach 2005) we predict the same result, i.e. that but will be used. The question explicitly asked by the interlocutor is not always precisely the same as the one taken up by the speaker who gives an answer (though of course they must be closely related, otherwise communication would not be possible). Our claim is that regardless of our assumptions about alternative sets for biased questions, the question answered by speaker B is Who "whether" lives in Amsterdam? with an alternative set of the form \{ John lives in Amsterdam, John doesn't live in Amsterdam, Peter lives in Amsterdam, Peter doesn't live in Amsterdam \}. 
variable is the polarity of the consequent. ${ }^{10}$ This specific subtype of a wh-yes/noquestion defines the ADVERSATIVE relation, or the ADVERSATIVE function in the semantic map in figure 3 on page 441. To keep the nodes of the semantic map disjoint one should assume that opposition involves all kinds of wh-yes/no-questions except this subtype of why-yes/no-questions, so when we talk about wh-yes/noquestions in the rest of the paper we will usually mean them in this narrow sense, to the exclusion of questions like (13).

As was already mentioned, semantic maps do not specify whether a certain multi-functional marker has a single abstract meaning, or as many different meanings as many functions of the semantic map it covers (or something in between). The representation of the different types of contrast in terms of the type of question under discussion can in fact be used in both ways. For example, the semantics of the English but can specify two options for the discourse topic: the wh-yes/no-questions in the narrow sense characteristic of opposition and whyyes/no-questions characteristic of the ADVERSATIVE, cf. table 1 on page 438 (multiple meanings). It can also be defined in terms of wh-yes/no-questions in the broad sense which covers both OPPOSITION and ADVERSATIVE (a single meaning). The latter approach is developed in Jasinskaja and Zeevat $(2008,2009)$. The English but is just a marker of wh-yes/no-topics in the broad sense and the Russian no marks whyyes/no-topics. The meanings of other markers can be defined in negative terms: e.g. the English and receives an abstract meaning as a marker of distinct answers to an unspecified type of question, but since it stands in a kind of paradigmatic relationship to but, the topic types for which but is more appropriate are excluded

[10] A few remarks are in order here. First, it still needs to be investigated whether negation in the negative alternatives needs to take scope over the whole consequent of BECAUSE or can have narrower scope within it. In any case, however, the consequents of positive and negative alternatives must be mutually exclusive.

Second, Because expresses a veridical relation, i.e. $\operatorname{BECAuse}(P, Q)$ entails both $P$ and $Q$. This means that distinct answers to a why-yes/no-question are always mutually exclusive: $\operatorname{BECAUSE}\left(P_{1}, Q\right) \wedge$ $\operatorname{BECAUSE}\left(P_{2}, \neg Q\right)$ entails both $Q$ and $\neg Q$. This is why adversative conjunctions like but and no always mark one of their conjuncts (usually the second one) as decisive:

(i)

a. The ring is expensive, but it is beautiful. (We will buy it)

b. The ring is beautiful, but it is expensive. (We will not buy it)

This is also why BECAUSE in adversatives is the argumentative BECAUSE. Adversatives are used when the issue whether $Q$ is not settled and is a matter of actual or possible dispute. The consequent of $P_{1}$ is a concession to the contrary view, while the consequent of $P_{2}$ is the proposition the speaker really endorses.

Third, one can think of other possible alternative sets that involve a causal relation, a wh-type variable and a $y / n$-type variable, but if they do not meet the specific conditions stated above, then they do not give rise to an ADVERSATIVE relation. An interesting case are corrections of causes, such as:

(ii) John hit Peter not because he was angry, but because he was drunk.

Here what is negated in the negative and asserted in the positive alternatives is not the consequent, but the identity of the cause. In contrast, the consequent John hit Peter holds in all the alternatives. 
from its marking domain (the blocking mechanism in Jasinskaja and Zeevat 2009). As a result, and admits all topic types except wh-yes/no-topics. It is sometimes difficult to decide which marker in a system should receive a positive definition, and which an abstract function restricted by blocking. The historical development of the system can give an effective clue: a relatively young marker that is expanding its set of functions should be defined positively, whereas an older marker that loses its functions to a newcomer is blocked by it. ${ }^{11}$

For the sake of readability, less technical terminology will be used in the rest of the paper. We will refer to $\left\langle\vec{x}_{w h}, y_{y / n}\right\rangle$-questions as wh-y/n and use the term 'double wh' for double variable questions that do not have a $y / n$-type variable. Double (variable) questions are thus a supertype of double wh and double wh-y/n. We will mainly talk about double questions assuming that the extension to multiple questions in general is trivial.

\section{[4] CORRECTION AS A TYPE OF CONTRAST}

This section will present an argument for the claim that both opposition (14) and CORRECTION (15) are realisations of a wh-yes/no strategy. At first glance these realisations look very different: (14) shows a contrastive topic-focus pattern, with a wh-type topic and polarity focus. ${ }^{12}$ In contrast, (15) has focal accent on the instantiations of the wh variable, while a contrastive topic seems to be missing altogether.
a. Oleg KURIT, a Roma ne KURIT.
Oleg smokes but Roma not smokes
Oleg smokes, but Roma doesn't.
b. Oleg ne KURIT, a Roma KURIT.
Oleg not smokes but Roma smokes
Oleg doesn't smoke, but Roma does.
a. Kurit Oleg, a ne ROMA.
smokes Oleg but not Roma
b. Kurit ne Oleg a ROMA.
smokes not Oleg but Roma

Moreover, Russian corrections obligatorily contain what is traditionally called constituent negation (in contrast to sentential negation, see Babby 1980, 2001; Brown

[11] A system of markers can also undergo reorganisation though, which can lead to an older marker acquiring a new positive meaning.

[12] Polarity focus both positive and negative is realised in Russian by a focal accent on the finite verb. The negative particle ne is a clitic, so it normally remains unaccented and does not function as a negative polarity focus exponent. In contrast, the finite verb is accented in both conjuncts in (14) even though the lexical verb itself is given at least in the second conjunct (normally, given material is deaccented). Thus the morphosyntactic constraints on focal accent placement overrule the considerations of givenness. 
1999), i.e. the negative particle ne appears immediately before the constituent to be corrected, cf. ne Roma, ne Oleg 'not Roma', 'not Oleg' in (15). The standard assumption is that sentences with constituent negation of the form not $X P$ presuppose that some object has property $P$ (Borschev et al. 2006), i.e. their meaning is similar to that of the English negated clefts: It is not John who smokes. In contrast, sentential negation is expressed by the negative particle appearing immediately before the finite verb, e.g. ne kurit, lit. 'not smokes' in (14). Sentential negation is possible in opposition sentences, but it cannot introduce the negative conjunct in corrections.

The goal of this section is to show, on the one hand, that all these structural differences fall within the range of options in addressing a wh-yes/no discourse topic, and on the other hand, that they correlate with precisely those functional features that make out the difference between the opPOSITION and the CORRECTION function. We will start with an overview of logical possibilities in how a wh-yes/no topic can be addressed in section [4.1]. Section [4.2] singles out one subtype of opposition sentences which bears the closest resemblance to correction in terms of those logical possibilities. The functional differences between the members of such minimal pairs are formulated. The last three sections relate those functional differences to sentential vs. constituent negation (section [4.3]) and differences in information structure (sections [4.4] and [4.5]).

\section{[4.1] Topic and focus in wh-yes/no}

There are always two ways to address a double question like Who ate what? You can go by people, or you can go by food. In the first case, the double question Who ate what? is split up into a series of single variable questions like What did John eat?, What did Bill eat?, etc., where the who-variable is instantiated by different persons from the relevant domain. In the second case, the double question is split up into subquestions Who ate the beans?, Who ate the carrots?, etc. According to Büring (2003), the choice between these two strategies determines which constituent is marked as contrastive topic and which one as focus: contrastive topic is the variable that is instantiated in the subquestion, i.e. people when you go by people, and food when you go by food; the focused constituent corresponds to the wh-variable in the subquestion.

Applying the same idea to wh-yes/no-questions we also get two possible strategies. Suppose the question is where "whether" John went. If we go by the locations instantiating the where variable, the question is split up into a series of yes/noquestions: Did John go to Paris?, Did John go to Berlin?, etc., as shown in figure 6 on the next page. In this case to Paris, to Berlin, etc., are contrastive topics $\left([. . .]_{T}\right)$, while the polarity is the focus $\left([. . .]_{F}\right)$, which surfaces as the focal accent on the auxiliary verb did or didn't. This is the structure underlying the canonical examples of opposition such as (8). 


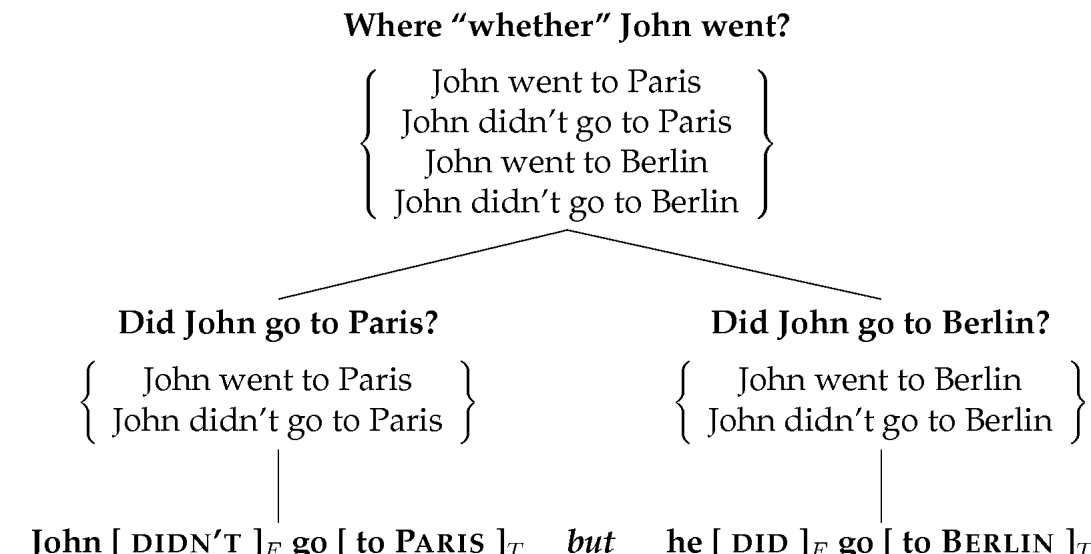

FIGURE 6: A wh-yes/no question split up by the wh variable

The other possibility is to instantiate the $y / n$-variable first, which splits up the wh-yes/no-question into two wh-questions, one addressing the positive part of the question and the other addressing the negative part, e.g. Where did John go?, Where didn't John go?, cf. figure 7 on the following page. In this case, the polarity would be marked as contrastive topic, and the answers to the where-question as focus. ${ }^{13}$

\section{[4.2] Corrections vs. oppositions with y/n-topics}

The main claim we would like to put forward is that corrections $(16-b) /(17-b)$ have the same underlying QUD structure as oppositions with $y / n$-topics (16-a)/(17-a), i.e. they both address an overarching wh-yes/no-question, which is split up by polarity as in figure 7 . The assertive propositional content of the conjuncts in both cases is the same: one conjunct states that it is not the case that John went to Paris, so it provides an answer to the question where John did not go; the other conjunct states that he went to Berlin, which is an answer to where John went. ${ }^{14}$

[13] Apparently, in English contrastive topics and foci can be marked just by intonation: topics receive a type B and foci a type A pitch accent (Büring 2003), which includes topics in situ that linearly follow the focus, as in figure 6. In German, there is a constraint that a topic must be followed by at least one focus in the same sentence (Büring 1997). In a sentence like that in figure 6 this can be achieved by topic fronting: $[\text { Nach Paris }]_{T}$ ist er $[\text { nicht }]_{F}$ gefahren, aber $[\text { nach Berlin }]_{T}[\text { schon }]_{F}$. Russian is more like German in this respect: accented contrastive topics have to precede foci; the melodic form of the pitch accent in turn is a less reliable cue to the topic/focus distinction than word order. There is a lot of variation in the form of the topic and focus accents (see Mehlhorn and Zybatow 2000, for a convincing illustration), and one and the same accent can mark both topic and focus depending on the context (Kodzasov 1996, p. 198).

[14] Since corrections have no contrastive topics, this contradicts Büring's (2003) claim that the presence of a strategy-a double question split up into single variable questions-is a sufficient condition for contrastive topic marking. The proposal developed in section [4.4] assumes that exceptions from this claim are possible when the pair or sequence of clauses realise two different strategies at the same time and the other strategy requires a structure without a contrastive topic. 


\section{Where "whether" John went?}

$$
\left\{\begin{array}{c}
\text { John went to Paris } \\
\text { John didn't go to Paris } \\
\text { John went to Berlin } \\
\text { John didn't go to Berlin }
\end{array}\right\}
$$

Where didn't John go?

$\left\{\begin{array}{c}\text { John didn't go to Paris } \\ \text { John didn't go to Berlin }\end{array}\right\}$
Where did John go?

$\left\{\begin{array}{c}\text { John went to Paris } \\ \text { John went to Berlin }\end{array}\right\}$

John [ DIDN'T $]_{T}$ go [ to PARIS $]_{F}$ but he $[\text { DID }]_{T}$ go [ to BERLIN $]_{F}$

FIGURE 7: A wh-yes/no question split up by the $y / n$ variable
a. John [ DIDN'T $]_{T}$ go [ to PARIS $]_{F}$, but he $[\text { DID }]_{T}$ go [ to BERLIN $]_{F}$.
b. John didn't go [ to PARIS $]_{F}$, but $[\text { to BERLIN }]_{F}$.
a. Oleg $[\text { ne EZDIL }]_{T}\left[\begin{array}{ll}\mathrm{v} & \text { PARIž, }\end{array}\right]_{F}$ a $[\text { EZDIL }]_{T}[\mathrm{v} \text { BERLIN. }]_{F}$ Oleg not went to Paris but went to Berlin
b. Oleg ezdil ne $[\mathrm{v} \text { PARIž, }]_{F}$ a $\left[\begin{array}{ll}\mathrm{v} & \text { BERLIN. }]_{F}\end{array}\right.$
Oleg went not to Paris but to Berlin

The functional differences between the two versions (a) and (b) lie in the domain of presuppositions and/or implicatures. The Russian sentence (17-a) is rather marked, presumably because it can only be felicitously used in a context where going and not going to different places has been at issue. It seems to presuppose that there is a place that oleg did not go to, and another place that he did go to, and specifies the first one to be Paris and the second to be Berlin. Its English counterpart (16-a) might sound less marked, but with really heavy contrastive topic accentuation on the auxiliaries it seems to have similar presuppositions.

In contrast, (16-b)/(17-b) only presupposes that John/Oleg went somewhere. The first conjunct negates that on a particular occasion John went to Paris, while the second conjunct states that on that occasion, in that event of going to a place, John went to Berlin rather than Paris. In other words, the wrong element Paris is replaced by the correct element Berlin in the description of a particular 'John went to $X$ '-event. We will refer to this property as replacivity, which is the most important distinctive feature of corrections among other kinds of contrast. ${ }^{15}$ Notice that in the (a) versions going to Paris and going to Berlin are treated as distinct

[15] The term is derived from Jacobs' replacive negation, i.e. a type of negation that requires a correction according to Jacobs $(1982,1991)$. The same property has also been referred to as 'denial by substitution' by Umbach (2004). 
possibilities, while in the corrections there is only one relevant occasion of going somewhere and it can either be to Paris, or to Berlin.

We have been using the term 'presuppose' in a rather non-technical sense here. In the following two sections we will make more precise assumptions about the nature of the 'presuppositions' involved and the linguistic means that contribute those presuppositions. Our discussion will concern primarily the Russian examples and will only touch upon a possible generalisation to English, which cannot be developed in detail in the present paper.

\section{[4.3] Negation and its presuppositions}

Our first assumption concerning negation will be that it 'presupposes' in a certain weak sense the proposition it negates. This is not the traditional, strong notion of presupposition which requires the presupposed material to be entailed by the context. It is enough that that material is somehow suggested, a possibility that could be entertained by someone on the basis of the current information state. Horn (1989) calls it 'supposition', others have used the term 'weak presupposition' (Zeevat 2008). It is a general characteristics of the pragmatics of overt negation that reflects the fact that one would never say that John didn't go to Paris unless it were somehow possible that John would go to Paris. This is equally true for English and Russian negation.

Of particular interest to us is the distinction between what is traditionally called sentential and constituent negation. Although we will stick to traditional terminology, one should keep in mind that it is rather misleading. It suggests that sentential negation takes scope over the whole sentence, while constituent negation takes narrower scope, but as was convincingly shown by Jacobs (1982) this is not at all the relevant distinction. From a syntactic point of view, sentential negation is verbal negation, i.e. the negative particle ne appears immediately before the finite verb and takes scope over the VP. It has received a lot of attention in the literature on Russian especially because it licenses the genitive of negation, as well as negative polarity (negative concord) items (Babby 1980, 2001; Brown 1999; Borschev et al. 2006). From a semantic point of view, its assertive content is just logical negation. For convenience, we will assume ne to denote $\lambda P \lambda Q[Q(\lambda x \neg P(x))]$ where $P$ is a property that stands for the meaning of the $\mathrm{VP}$, and $Q$ a quantifier denoted by the argument (typically, the subject) that still needs to be supplied to make it a full proposition. ${ }^{16}$ Accordingly, the weak presupposition it introduces is simply $Q(P)$. For example in (18), $Q$ is $\lambda P[P($ oleg $)]$ and $P$ is smoke which gives us $\neg$ smoke(Oleg) for the assertive meaning of the sentence, and smoke(Oleg) for its weak presupposition.

[16] It is immaterial for the present discussion whether the given logical type is basic for the Russian negative particle, or the result of syntactically or semantically motivated abstraction operations on a lower basic type. 
(18) Oleg ne kurit

Oleg not smokes

Oleg doesn't smoke.

In contrast, constituent negation is marked by the particle ne appearing in front of "the constituent that is negated," cf. (19), which can be (almost) any constituent: quantificational and referential DPs, PPs, etc., and in particular also VPs or whole sentences. Thus from a syntactic point of view, constituent negation is crosscategorial negation (at least superficially). ${ }^{17}$ Normally, the negated constituent receives focal accent.
a. ne $[\text { OLEG }]_{F}$ kurit
not Oleg smokes
b. kurit ne $[\text { OLEG }]_{F}$
smokes not Oleg
It is not Oleg that smokes.

Semantically, "the constituent that is negated" does not just mean that negation takes scope over that constituent in the standard sense. Sentences with constituent negation have altogether rather different semantics from the sententially negated ones. Constituent negation is typically assumed to presuppose the positive part of the sentence, e.g. (19) presupposes that someone smokes (Borschev et al.2006). In fact, a stronger assumption seems justified: Russian sentences with constituent negation have roughly the same semantics as e.g. the English negated specificational (pseudo)cleft sentences, i.e. It is not Oleg that smokes, or Who smokes is not Oleg.

The first approximation of how this meaning is composed is shown in figure 8 on the next page. Negation applies to the property of being Oleg $(\lambda x[x=$ Oleg $])$ associated with the negated DP, and takes the quantifier who smokes ( $\lambda P \forall x[[x \in$ $C \wedge \operatorname{smoke}(x)] \rightarrow P(x)])$ associated with the fronted verb kurit as its second argument. Simplifying again, the positive part of the sentence kurit 'who smokes' is represented as a universal quantifier. ${ }^{18}$ Its domain restriction $C$ depends on the context of utterance and realises the idea that only relevant individuals that smoke are concerned. Notice that the same semantics is assigned to constituent

[17] This means that when the negative particle appears immediately before the finite verb the sentence is ambiguous between a constituent and a sentential negation reading.

[18] It is more common to treat free relatives, which participate in pseudocleft constructions, as definites, or maximal individuals (Jacobson 1995; Rullmann 1995). Notions like maximality, however, implicitly involve universal quantification. 


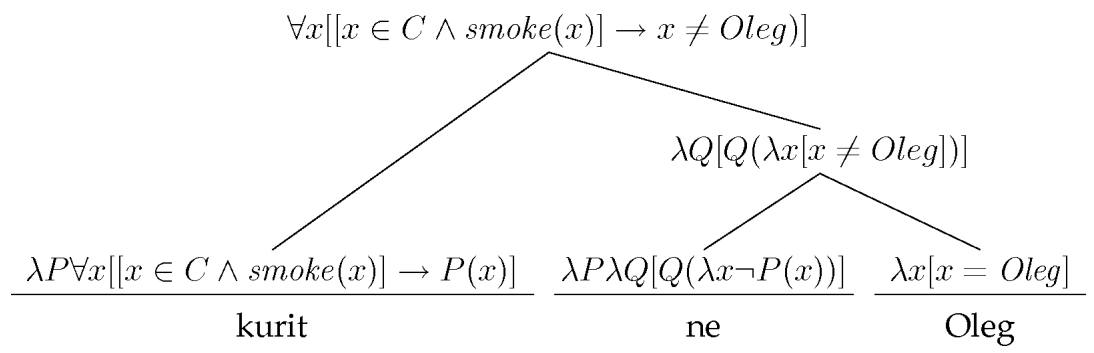

FIGURE 8: Semantic composition for a sentence with constituent negation, (19-b)

and sentential negation, ${ }^{19}$ all the difference comes from the meanings associated with the rest of the sentence-the negated and the positive parts. We assume that these differences are accounted for by whatever syntactic operations are responsible for the marked word order and accentuation, and especially for the position of the negative particle in sentences with constituent negation. However, no details of the syntactic analysis will be discussed. ${ }^{20}$

As far as presupposition is concerned, first of all, the fronted verb kurit, just like a free relative who smokes (and Fregean definites), introduces an existential presupposition that someone relevant $(x \in C)$ smokes, i.e. $\exists x[x \in C \wedge \operatorname{smoke}(x)]$. This accounts for the intuitions of Borschev et al. (2006). Second, negation weakly presupposes what it negates, i.e. in the present case it is the meaning of a positive (pseudo)cleft It is Oleg that smokes or Who smokes is Oleg: $\forall x[[x \in C \wedge \operatorname{smoke}(x)] \rightarrow$ $x=\mathrm{Oleg}]$. Notice that in conjunction with the existential presupposition this is equivalent to saying that Oleg is an exhaustive answer to the question Who smokes?, which can also be roughly paraphrased as only Oleg smokes. In other words, a sentence with constituent negation like (19) presupposes that the question Who smokes? has previously been answered exhaustively, and the answer was Oleg (or this answer was expected or possible). Thus constituent negation brings in ex-

[19] This is partly due to the wide scope of the quantifier $Q$ over negation, which in turn only takes scope over the predicate $P$ in our definition. In other words, $P$ represents the negated and $Q$ the positive part of the sentence. This might not be general enough to account for all possible readings of sentences with sentential negation. Certainly, a more general and principled analysis can be provided in the future.

[20] If constituent negation applies to the VP, as in (i), the sentence is to be interpreted roughly as what oleg does isn't smoke, i.e. the fronted DP Oleg represents in this case a quantifier over eventualities that involve Oleg as agent. Once again, this quantifier must result from the interpretation of syntactic substructures of the sentence which in turn result from presumably the same syntactic operations as those that apply in sentences like (19) with DP constituent negation. The difference is that here the surface word order happens to coincide with the unmarked word order with the negative particle before the finite verb, so the sentence Oleg ne kurit is ambiguous between the constituent and the sentential negation reading.

(i) Oleg ne kurit, a p'jot.

Oleg not smokes but drinks 
haustivity into the semantics of the sentence. As we will see in the following section exhaustivity is one of the crucial ingredients of replacivity in corrections.

From a pragmatic point of view, the distinction between constituent and sentential negation in Russian is close to the replacive vs. non-replacive distinction introduced by Jacobs $(1982,1991)$. Replacive negation calls for a correction. The sentences in (19), for example, sound incomplete without a continuation stating who actually smokes. This incompleteness does not lead to ungrammaticality, but there is a clear sense that after (19) the question Who smokes instead? is somehow "in the air."

\section{[4.4] Exhaustivity and replacivity}

Coming back to corrections, let us first show that their replacivity property can be derived from the assumption that one conjunct negates an exhaustive answer to a question, while the other conjunct gives a new exhaustive answer to the same question. As was argued in the previous section, the negative conjunct in (20) presupposes that Oleg is an exhaustive answer to the question Who smokes?, which can be derived by applying, let's say, Groenendijk and Stokhof's (1984) exhaustivity operator $\mathrm{EXH}^{21}$ to the quantifier that represents the meaning of the answer $\lambda P[P($ Oleg $)]$, and applying the resulting exhaustive quantifier to the predicate of the question $\lambda x[x \in C \wedge \operatorname{smoke}(x)]$, i.e. $\operatorname{ExH}(\lambda P[P($ oleg $)])(\lambda x[x \in C \wedge$ smoke $(x)])$, which is equivalent to $\forall x[[x \in C \wedge \operatorname{smoke}(x)] \leftrightarrow x=$ Oleg $]$.

(20) Kurit ne OlEg, a ROMA.

smokes not Oleg but Roma

Not Oleg, but Roma smokes.

The proposition $\forall x[[x \in C \wedge \operatorname{smoke}(x)] \leftrightarrow x=$ Oleg $]$ is "removed" from the information state after the processing of the incompatible proposition $\forall x[[x \in$ $C \wedge \operatorname{smoke}(x)] \rightarrow x \neq$ oleg] that constitutes the content of the negative conjunct. ${ }^{22}$ For Roma to replace Oleg as the one relevant person who smokes, we have to assume that the positive conjunct provides another exhaustive answer to the question Who smokes?: $\forall x[[x \in C \wedge \operatorname{smoke}(x)] \leftrightarrow x=$ Roma $]$. Given that Oleg and Roma are two distinct persons, these two exhaustive answers are mutually incompatible. ${ }^{23}$ Moreover, it is essential that the question with respect to which

[21] For reference, this is one of the existing formulations of Groenendijk and Stokhof's exhaustivity: EXH = $\lambda \mathcal{Q} \lambda P\left[\mathcal{Q}(P) \wedge \neg \exists P^{\prime}\left[\mathcal{Q}\left(P^{\prime}\right) \wedge P \neq P^{\prime} \wedge \forall x\left[P^{\prime}(x) \rightarrow P(x)\right]\right]\right]$.

[22] One would have to assume some kind of non-monotonic notion of update (such as e.g. Asher and Lascarides 2003) to make such "removal" of incompatible propositions possible. Otherwise we reach an absurd information state.

[23] The distinctness of oleg and Roma would normally be part of general world knowledge, but it also follows from the requirement that the conjuncts of a contrastive conjunction provide distinct answers to the same question. In the present case, Oleg and Roma would be distinct instantiations of the wh-variable in a wh-yes/no-question. 
the answers are exhaustivized is strictly the same, which also means the same instantiation for the implicit contextual restriction $C$. The question might, and normally would also contain other implicit restrictions that constrain, for instance, the time and location of the relevant smoking events. Keeping all those restrictions the same in the two instances of exhaustivization ensures that Roma comes in place of Oleg as the only relevant smoker on that particular relevant occasion.

The idea to derive replacivity and mutual exclusiveness of the conjuncts in corrections from the assumption that the conjuncts represent exhaustive answers to the same question has been previously developed by Kasimir (2006) in her account of the German sondern. Our proposal implements the same idea, except that if Kasimir makes exhaustivity of the conjuncts a presupposition conventionally associated with sondern, in our case it is not part of the semantics of the Russian $a$, but is contributed by constituent negation, which is obligatory in corrections. ${ }^{24}$

[24] There are some curious exceptions to the claim that corrections always involve constituent negation. In (i), both the negative existential predicate net (Borschev et al. 2006) and the negative concord item ni odnogo '(not) a single' indicate sentential negation. In (ii) it is the negative concord item nikakix 'no'. Nevertheless, both are followed by a correction with $a$.

(i) Na ètoj grjadke net ni odnogo ovošča a tol'ko sornjaki. on this patch there isn't no single vegetable but only weed

(ii) Oleg ne ugonjal nikakix mašin, a igral ves'večer so mnoj v karty Oleg not high-jacked no cars but played all evening with me in cards Oleg didn't high-jack any cars, but was playing cards with me all evening.

Possibly, what is going on here is when the speaker utters the first clause she is not planning yet to produce a correction. The plan to make it into a correction appears after the production of the negative clause, so it is reinterpreted post hoc as one with a constituent negation: There are no vegetables $\Rightarrow$ What there is is not vegetables; Oleg didn't high-jack any cars $\Rightarrow$ What Oleg was doing is not high-jacking cars. This is supported by the fact that, although generally Russian corrections with $a$ can be turned around-positive conjunct first, negative second, cf. (15-a) vs. (15-b)-this is not possible in these examples, cf. (iii-b) and (iv-b). This is because by the time the speaker reaches the negative conjunct, she is already committed to the plan of producing a correction, so constituent negation must be used. Notice that the versions without the negative concord items (iii-b) and (iv-b) are felicitous.

(iii) Na ètoj grjadke tol'ko sornjaki, on this patch only weed
a. \# a (net) ni odnogo ovošča. but there isn't no single vegetable
b. a ne ovošči.
but not vegetables

(iv) Olegigral ves' večer so mnoj v karty, Oleg played all evening with me in cards
a. \# a ne ugonjal nikakix mašin. but not high-jacked no cars
b. a ne ugonjal mašiny. but not high-jacked cars 
More precisely, constituent negation provides the exhaustivity of the presupposed proposition to be corrected, while the exhaustivity of the positive conjunct still needs a short comment.

It is common to assume that answers to a question are interpreted exhaustively by default, even if they do not contain linguistic devices that encode exhaustivity, like only or cleft constructions. Presumably, default exhaustivization of this sort takes place in the positive conjunct in corrections. However, what guarantees that the question with respect to which the answer is exhaustivized is the same (including all the implicit contextual restrictions) as the one with respect to which the presupposed incorrect answer is exhaustivized? An anonymous reviewer has suggested that it should be adopted as a general characteristic of corrections that the negative and the positive conjunct address the same single wh-question like Who smokes? in (20), rather than a double wh-yes/no-question which falls apart into a negative and a positive subquestion Who doesn't smoke? and Who smokes? as was proposed in section [4.2]. Indeed, this could be made to guarantee the preservation of the same contextual restrictions. Also, this construction of the discourse topic (in contrast to the double wh-yes/no strategy) would explain the characteristic information structure of corrections, i.e. their accentuation and word order, and in particular the absence of contrastive topics, cf. (14) and (15). Notice also that Russian sentences with constituent negation are more appropriate as answers to positive than to negative questions, so (22-a) is more appropriate after (21-a) and (22-b) after (21-b).
a. Kto kurit?
who smokes
'Who smokes?'
b. Kto ne kurit?
who not smokes
'Who doesn't smoke?'

a. Kurit ne Oleg smokes not Oleg 'It is not Oleg who smokes.'

b. Ne kurit Oleg not smokes Oleg 'It is Oleg who doesn't smoke.'

Moreover, if the default exhaustivization of a negative answer to a positive wh-question provided something to the effect of the Russian sentences with constituent negation or the English negated clefts-EXH(not John) (smokes) = 'it is not John who smokes' (including the weak presupposition of the corresponding positive sentence 'it is John who smokes')-then the present analysis could be easily extended to English corrections, where neither the positive nor the negative conjunct need to contain any linguistic devices that encode exhaustivity by convention:

(23) John didn't go to PARIS, but to BERLIN. 
Unfortunately, this is not the prediction made by most existing theories of default exhaustivization. For example, Groenendijk and Stokhof (1984) predict that the exhaustive interpretation of not to Paris with respect to the question Where did John go? implies that John didn't go anywhere (which is obviously wrong); von Stechow and Zimmermann (1984) predict in the same case that John went everywhere else except Paris. ${ }^{25}$ In general, this is incompatible with the exhaustive interpretation of the positive conjunct which says that John went only to Berlin. Or rather, the two exhaustive interpretations are only compatible on the assumption that Paris and Berlin are the only relevant places under discussion: $C=\{$ Paris, Berlin $\}$. However, on this assumption the exhaustive interpretation of the negative conjunct already implies that John went (only) to Berlin, so the positive conjunct is made completely redundant. This contradicts the intuition that the negative conjunct in (23) leaves it open where John actually went instead of Paris, whereas this information is provided no sooner than in the positive conjunct. Schulz and van Rooij (2006) argue that the exhaustive interpretation of a negative answer to a positive wh-question should be identical with its literal meaning, i.e. John didn't go to Paris, but it is unknown whether he went anywhere else. This would at least be compatible with the intuition that the positive conjunct provides a further specification of the place John went to in relation to 'some place other than Paris'. However, the way Schulz and van Rooij (2006) achieve this result in their theory is hard to reconcile with our assumptions about corrections. In their proposal, the fact that the speaker uses negation in an answer to a positive question should be seen as a signal that the speaker deviates from the standard form for answering positive questions, and ultimately as an indication of the speaker's limited competence on the issue Where did John go? The assumption of limited competence blocks inferences about other places John could have gone to. However, the normal exhaustive reading of the positive conjunct, that John went to Berlin and nowhere else, can only be derived on the assumption of the speaker's full competence on the issue where John went. In other words, in order to make Schulz and van Rooij's proposal work for us, one has to assume that the speaker is incompetent on the current question when uttering the negative conjunct, but competent on the very same question when uttering the positive conjunct in the very next instant. This assumption seems rather implausible. Moreover, none of these approaches predicts that exhaustivized negative answers to positive questions (weakly) presuppose an exhaustive positive answer that they negate-an assumption which is essential in our derivation of replacivity. It seems, what we need is an exhaustivity operator that makes roughly $\neg[\max (\lambda x[$ John went to $x])=$ Paris $]$ out of Where did John go? John didn't go

[25] Basically, von Stechow and Zimmermann (1984) exhaustivize with respect to the negated predicate, i.e. the question Where didn't John go? If Paris is the only relevant place where John didn't go, then he must have gone to all other relevant places. 


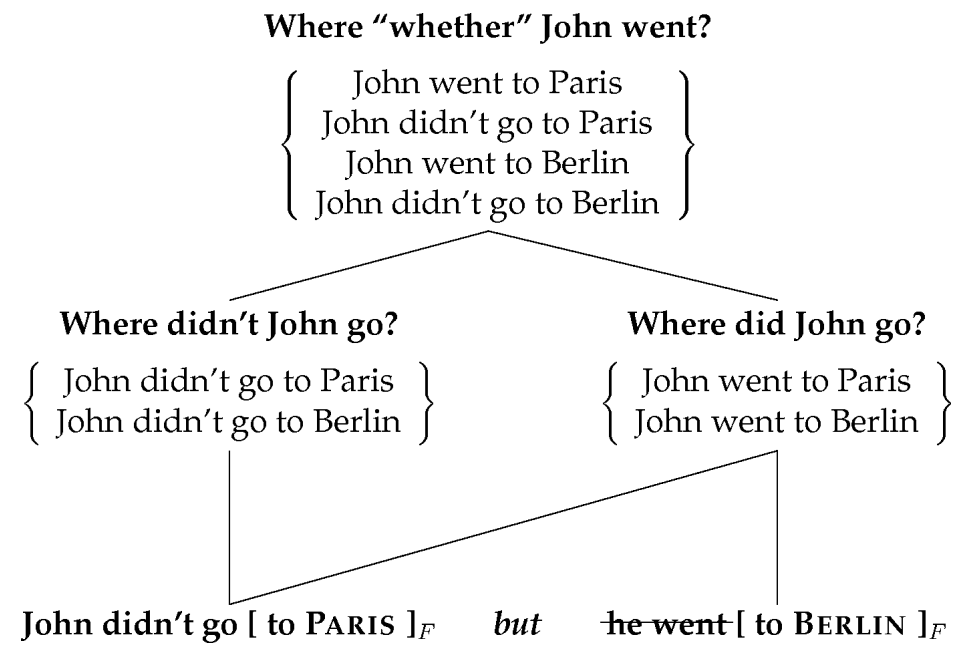

FIGURE 9: Discourse topics in corrections: The negative conjunct addresses both the negative part of the wh-yes/no question and shares the positive single wh-question with the positive conjunct

to Paris, where max returns the maximal (possibly plural) individual that has the property $\lambda x$ [John went to $x]$ (cf. Rullmann 1995). This is close to Zeevat's (1994) notion of default exhaustivity, with the additional assumption that negation is neither part of the answer (or focus), nor of the question (or background), but takes scope over the whole proposition after the application of the exhaustivity operator to the answer and the question.

In sum, the assumption that the negative and the positive conjunct both answer the same single variable wh-question establishes a link between the deviant information structure of corrections (only foci, but no contrastive topics) and their replacivity property. However, does this mean that our view of corrections as instances of contrast that address double wh-yes/no-questions should be abandoned? In fact, it seems that corrections simply have this hybrid nature: they answer a single wh-question and at the same time a double wh-yes/no-question split up into a negative and a positive part, as shown in figure 9. The single whtopic construal is responsible for the information structure and replacivity of corrections, while the wh-yes/no-construal accounts for the fact that there must be exactly one negative and one positive conjunct, as well as for other properties that corrections share with contrast relations, in particular the use of contrastive markers like the English but and the Russian $a$. In other words, this hybrid nature is what distinguishes corrections from oppositions with $y / n$-topics. Oppositions only have overarching wh-y/n-topics, cf. figures 6 on page 449 and 7 on page 450 , while corrections are defined by a combination of the two topic types. 
Of course, a number of hard questions arise once we allow for such non-tree structures as in figure 9 on the facing page, where one and the same utterance may be immediately dominated by two distinct topic questions. What constrains the set of questions addressed by the same utterance? Without strong constraints on this set the whole QUD-based theory of discourse structure loses its predictive power. What does it depend on, for instance, which of the questions addressed by the utterance determines its information structure? Although we cannot address these issues in detail here, it should be said that there is a number of phenomena that motivate structures with sentences dominated by more than one question. One of them is second occurrence focus, where the accentuation pattern suggests one construction of the discourse topic whereas a focus-sensitive particle requires a different construction to set its domain correctly. This group of phenomena still awaits a systematic study.

\section{[4.5] Why oppositions with $\mathrm{y} / \mathrm{n}$-topics are rare}

Finally, a few remarks are due on the observation made in section [4.2] that oppositions with contrastive polarity topics are barely acceptable and require very special context to be felicitous (cf. the discussion of (16-a)/(17-a)). This would follow naturally on the assumption that there is a preference for contrastive topics that are also given, contextually activated and talked about. For Büring's example (24) it implies that if Fred and Mary were previously mentioned and are talked about, one would prefer to go by people making Fred and Mary the contrastive topic as in (24-a). In contrast, if the talk is about food, so the beans and the eggplant were mentioned or are accessible via a bridging inference while Fred and Mary are new then it might be better to go by food and choose the structure in (24-b).

(24) a. $[\text { Fred }]_{T}$ ate $[\text { the beans }]_{F},[\text { Mary }]_{T}$ ate $[\text { the eggplant }]_{F}$.

b. $[\text { Fred }]_{F}$ ate $[\text { the beans }]_{T},[\text { Mary }]_{F}$ ate $[\text { the eggplant }]_{T}$.

This is not to suggest that the notions of givenness, referent activation or aboutness topic should be conflated with the notion of contrastive topic. Rather, just like subjecthood, definiteness and animacy are distinct notions which tend to fall together-subjects are definite and animate most of the time (Aissen 2003; Zeevat and Jäger 2002) - different varieties of topic tend to be aligned in a similar way. That is, there is perhaps no categorical requirement that contrastive topics be also aboutness topics or given, but an optimisation process prefers sentences with given contrastive aboutness topics.

In this light it is obvious that polarity values make bad topics. Although we have seen that in Büring's theory they are just as good contrastive topics as they are foci, one has to admit that they make little sense as aboutness topics or as entities subject to activation in memory. Therefore ceteris paribus, splitting by the 
wh-variable (25-b), which makes a usual term the contrastive topic, is always preferred to splitting by the yes/no-variable (25-a). In fact, what seems like a yes/notopic in (25-a) is most probably something bigger-perhaps, an open proposition of Oleg not going vs. Oleg going somewhere. These are entities that can be activated and talked about. This would explain why (25-a) is only appropriate in a context where Oleg not going and Oleg going somewhere (and not just yes and no) are somehow activated or salient. ${ }^{26}$
a. Oleg $[\text { ne EZDIL }]_{T}[\mathrm{v} \text { PARIŽ, }]_{F}$ a $[\text { EZDIL }]_{T}\left[\begin{array}{ll}\mathrm{v} & \text { BERLIN. }]_{F}\end{array}\right.$ Oleg not went to Paris butwent to Berlin
b. Oleg $[\mathrm{v} \text { PARIŽ }]_{T}[\text { ne EZDIL, }]_{F}$ a $[\mathrm{v} \text { BERLIN }]_{T}[\text { EZDIL. }]_{F}$ Oleg to Paris not went but to Berlin went

\section{[5] CONCLUSIONS AND OUTLOOK}

We started with the observation that correction is often signalled by the same markers as contrast, especially the opposition type of contrast. This regularity is captured by universal semantic maps of Malchukov (2004) and Mauri (2008), and the one proposed in section [2], figure 3. Now we can say more about the nature of the links between the functions CONTRASTIVE COMPARISON, OPPOSITION, ADVERSATIVE and CORRECTION. All of them are relations between distinct answers to various subsorts of multiple variable questions. Moreover, ADVERSATIVE is more closely related to OPPOSITION than to CONTRASTIVE COMPARISON because both ADVERSATIVE and OPPOSITION involve wh-yes/no-questions-questions whose one variable is of the polarity type. In this paper we have shown that CORRECTION can be seen as another special case of a wh-yes/no-strategy. Its specific characteristics are: (a) the multiple variable wh-yes/no-question Who "whether" $P$ ? is split into single variable subquestions by polarity, i.e. one subquestion addresses the positive (Who $P$ ?) and the other the negative part of the question (Who not $P$ ?) ; (b) one conjunct negates that $A$ is an exhaustive answer to the question Who $P$ ? while the other conjunct asserts that $B$ is. Given an appropriate notion of exhaustivity, the latter condition could also be derived from the assumption that both conjuncts give exhaustive answers to the positive Who $P$ ? question (i.e. the negative con-

[26] Even in languages like German which seem to allow for contrastive topicalisation (movement to the prefield position) of just the negative particle as in (i), the contextual appropriateness conditions of such sentences are similar to those of (25-a). It is the open propositions of her confessing vs. not confessing something that serve as the contextual anchor, rather than just yes and no.

(i) Sie has zugegeben, den Mann ausgeraubt zu haben. Nicht aber hat sie gestanden, ihn she hat confessed the man robbed to have not but has she confessed him ermordet zu haben. murdered to have

'She confessed that she robbed, but not that she murdered the man.' 
junct addresses both the negative and the positive part of the question). Thus what makes CORRECTION and OPPOSITION so closely related is again the fact that they both answer a wh-yes/no-question. In fact, in light of the present proposal one would have to define opposition as a relation between distinct answers to a wh-yes/no-question except the subtypes characteristic of corrections and adversatives-therefore its position on the crossroads. In other words it is the similarities and differences between the types of discourse topic that determine which functions on the contrast semantics map are more closely, and which are less closely related.

The other question that we asked in the beginning of the paper was whether the combination of negation and $a$ in Russian (or but in English) is a fixed collocation with correction semantics, or whether the correction semantics results independently from the properties of $a$ as a general contrast marker in combination with the properties of negation. We have gone a long way in proving the latter point. Indeed, using the same notion of discourse topic one can define a single general meaning for $a$ : a relation between distinct answers to a multiple variable question whose variable types are unspecified (except the why-yes/no-questions of the adversative type, because for those conjunction no is the preferred marker), as this is done e.g. in Jasinskaja and Zeevat (2008). Since correction is a special case of wh-yes/no, which in turn is a special case of a multiple variable question, correction falls within the domain of $a$. The same holds for the English but: since but marks wh-yes/no-strategies of all kinds, it can in particular be used for correction.

In turn, the replacivity property and the presuppositions that we find specifically in corrections could all be put on the account of negation and exhaustivity. The Russian case was relatively easy to handle because corrections in Russian require constituent negation, and exhaustivity is simply built into the conventional semantics of sentences with constituent negation. The same approach could be applied to English if negation is made to interact with pragmatic exhaustivity in the right way.

In sum, this paper offers a theory of correction that explains its marking patterns in Russian and English and its most central semantic and pragmatic properties.

There are still many loose ends, unanswered questions and problems. Let's mention just one of them because we did not get a chance to discuss it in the body of the paper. The semantic map proposed in section [2], figure 3, only connects the CORRECTION function to OPPOSITION. At least, this arrangement of functions is best motivated from the point of view of the theory of contrast based on topic question types. According to the strong contiguity claim of the semantic map approach, this predicts that whenever a contrast marker is used for CORRECTION it should also be able to mark OPPOSITION. Or in other words, if CONTRASTIVE COM- 
PARISON and CORRECTION are marked in the same way, then OPPOSITION should be marked in the same way as well. Japanese is a language that falsifies this prediction. The relevant contrastive relations can be conveyed in Japanese by the converb marker -te (-de), roughly 'and', and the clause final marker -ga, roughly 'but' (Mauri 2008). - Ga has an ADVERSATIVE function. -Te looks like a general additive marker which in particular can be used for CONTRASTIVE COMPARISON. It is also used in corrections, as in the following example from Mauri (2008, p. 134):

(26) tyuumonsi-ta-no-wa kootya-de-naku-te koohii-desu order-PRF-NR-TOP tea-COP-NEG-AND coffee-COP What I ordered is not tea, but it's coffee.

However, opposition in examples like John likes football, but Bill doesn't is expressed by the marker -ga. This makes the marking region of -te discontinuous.

John-wa sakka-ga suki da-ga Bill-wa suki ja-nai John-TOP football-NOM likes COP-but Bill-TOP likes COP-NEG John likes football, but Bill doesn't.

An ad hoc solution would be to draw an additional arc between CORRECTION and CONTRASTIVE COMPARISON, though this is not so appealing since it makes the semantic map weaker. Another possibility is to use the weak, diachronic interpretation of semantic maps: if -te were an older marker with a general additive/contrastive function (distinct answers to an unspecified type of question), while -ga were expanding from a purely adversative marker and took over opPOSITION as a new function, it would create a 'hole' in the marking region of te. Finally, the single meaning approach would come to terms with this deviant marking pattern if it could be shown that there is some independent reason that prevents - $g a$ from being used in corrections. Then -te once again receives a general function of marking distinct answers to an unspecified type of question. This is so general that it covers in particular also coRRECTION. Wh-yes/no-questions are excluded from the marking domain of -te since there is a better marker for them, namely -ga. However, the CORRECTION-type wh-yes/no-questions are not excluded if there for some independent considerations - $g a$ is not the preferred marker for that question type. Which of these or other solutions is right is to be clarified by future research.

\section{REFERENCES}

Aissen, J. (2003). Differential object marking: Iconicity vs. economy. Natural Language and Linguistic Theory, 21(3):435-483.

Anscombre, J. C. and Ducrot, O. (1977). Deux mais en français? Lingua, 43(1):23-40. 
Asher, N. and Lascarides, A. (2003). Logics of Conversation. Studies in Natural Language Processing. Cambridge University Press.

Babby, L. H. (1980). Existential sentences and negation in Russian. Karoma Publishers.

Babby, L. H. (2001). The genitive of negation: a unified analysis. In Annual Workshop on Formal Approaches to Slavic Linguistics, volume 9, pages 39-55. Univ of Michigan/Michigan Slavic.

Blakemore, D. (1987). Semantic Constraints on Relevance. Basil Blackwell.

Borschev, V., Paducheva, E., Partee, B., Testelets, Y., and Yanovich, I. (2006). Sentential and constituent negation in Russian BE-sentences revisited. In Formal Approaches to Slavic Linguistics: The Princeton Meeting 2005 (FASL 14), pages 50-65.

Brown, S. (1999). The syntax of negation in Russian: A minimalist approach. CSLI Publications.

Büring, D. (1997). The Meaning of Topic and Focus: The 59th Street Bridge Accent. Routledge, London.

Büring, D. (2003). On D-trees, beans and B-accents. Linguistics and Philosophy, 26:511-545.

Foolen, A. (1991). Polyfunctionality and the semantics of adversative conjunctions. Multilingua, 10(1/2):79-92.

Fougeron, I. (1990). A et les rapport interphrastiques en russe contemporain. Revue des études slaves, LXII(1-2):125-137.

Groenendijk, J. and Stokhof, M. (1984). Studies in the Semantics of Questions and the Pragmatics of Answers. PhD thesis, University of Amsterdam.

Hamblin, C. L. (1973). Questions in Montague English. Foundations of Language, 10:41-53.

Haspelmath, M. (2003). The geometry of grammatical meaning: Semantic maps and cross-linguistic comparison. In Tomasello, M., editor, The new psychology of language: Cognitive and functional approaches to language structure, volume 2, pages 211-243. New York.

Horn, L. R. (1989). A Natural History of Negation. University of Chicago Press.

Jacobs, J. (1982). Syntax und Semantik der Negation im Deutschen. Fink, München. 
Jacobs, J. (1991). Negation. In von Stechow, A. and Wunderlich, D., editors, Semantik. Ein Internationales Handbuch der Zeitgenössischen Forschung. De Gruyter, Berlin.

Jacobson, P. (1995). On the quantificational force of English free relatives. In Bach, E., Jelinek, E., Kratzer, A., and Partee, B. H., editors, Quantification in natural languages, pages 451-486. Kluwer Academic Publishers.

Janda, L. A. (2009). What is the role of semantic maps in cognitive linguistics. In Stalmaszczyk, P. and Oleksy, W., editors, Studies in honor of Barbara LewandowskaTomaszczyk, pages 105-124. Peter Lang Publishers, Frankfurt am Main.

Jasinskaja, K. and Zeevat, H. (2008). Explaining additive, adversative and contrast marking in Russian and English. Revue de Sémantique et Pragmatique, 24:65-91.

Jasinskaja, K. and Zeevat, H. (2009). Explaining conjunction systems: Russian, English, German. In Riester, A. and Solstad, T., editors, Proceedings of Sinn und Bedeutung 13, volume 5 of SinSpeC. Working Papers of the SFB 732. University of Stuttgart.

Kasimir, E. (2006). On 'nicht ... sondern ...' (contrastive 'not ... but ...'). In Ishihara, S., Schmitz, M., and Schwarz, A., editors, Interdisciplinary Studies in Information Structure, volume 5, pages 107-151.

Kodzasov, S. V. (1996). Zakony frazovoj akcentuacii. In Nikolaeva, T. M., editor, Prosodičeskij stroj russkoj reči, pages 181-204. Institut russkogo jazyka Rossijskoj akademii nauk, Moskva.

Kreidlin, G. E. and Paducheva, E. V. (1974a). Vzaimodejstvie associativnyx svjazej i aktual'nogo členenija v predloženijax s sojuzom $a$. Naučno-texničeskaja informacija, 1974(10):32-37. Ser. 2, Avtomatizacija obrabotki tekstov.

Kreidlin, G. E. and Paducheva, E. V. (1974b). Značenie i sintaksičeskie svojstva sojuza $a$. Naučno-texničeskaja informacija, 1974(9):31-37. Ser. 2, Avtomatizacija obrabotki tekstov.

Lakoff, R. (1971). If's, and's and but's about conjunction. In Fillmore, C. J. and Langendoen, D. T., editors, Studies in Linguistic Semantics, pages 114-149. Holt, Rinehart and Winston, New York.

Malchukov, A. L. (2004). Towards a semantic typology of adversative and contrast marking. Journal of Semantics, 21:177-198.

Mauri, C. (2008). Coordination Relations in the Languages of Europe and Beyond. Mouton de Gruyter. 
Mehlhorn, G. and Zybatow, G. (2000). Alte und neue Hüte der russischen Informationsstruktur. In Linguistische Arbeitsberichte, volume 74. Institut für Linguistik, Universität Leipzig.

Roberts, C. (1996). Information structure in discourse: Towards an integrated formal theory of pragmatics. OSU Working Papers in Linguistics, 49:91-136.

Rullmann, H. (1995). Maximality in the Semantics of Wh-constructions. PhD thesis, University of Massachusetts at Amherst.

Sannikov, V. Z. (1989). Russkie sočinitel'nye konstrukcii. Nauka, Moskva.

Schulz, K. and van Rooij, R. (2006). Pragmatic meaning and non-monotonic reasoning: The case of exhaustive interpretation. Linguistics and Philosophy, 29(2):205-250.

Sweetser, E. (1990). From Etymology to Pragmatics: Metaphorical and Cultural Aspects of Semantic Structure. Cambridge University Press.

Umbach, C. (2004). On the notion of contrast in infromation structure and discourse structure. Journal of Semantics, 21:155-175.

Umbach, C. (2005). Contrast and information structure: A focus-based analysis of but. Linguistics, 43(1):207-232.

Uryson, E. V. (2002). Sojuz a kak signal "povorota povestvovanija”. In Arutjunova, N. D., editor, Logičeskij analiz jazyka. Semantika načala i konca, pages 348-357. Indrik, Moskva.

von Stechow, A. and Zimmermann, T. E. (1984). Term answers and contextual change. Linguistics, 22:3-40.

Zeevat, H. (1994). Applying an exhaustivity operator in update semantics. In Kamp, H., editor, Ellipsis, Tense and Questions, pages 233-269. ILLC, Amsterdam. Dyana-2 deliverable R2.2.B.

Zeevat, H. (2008). Only as a mirative particle. Ms. University of Amsterdam.

Zeevat, H. and Jäger, G. (2002). A reinterpretation of syntactic alignment. In de Jongh, D., Zeevat, H., and Nilsenova, M., editors, Proceedings of the 3rd and 4th International Symposium on Language, Logic and Computation, Amsterdam. ILLC. 
AUTHOR CONTACT INFORMATION

Katja Jasinskaja

Centre for Advanced Study

Drammensveien 78

0271 Oslo

Norway

katja.jasinskaja@cas.uio.no 